\title{
ELETROFORESE: CONCEITOS E APLICAÇÕES
}

Evelyn de Oliveira ${ }^{1}$, Thays de Campos Trentin ${ }^{2}$, Fabrício Camargo ${ }^{3}$, Yago Danilo Pereira Pinto ${ }^{4}$ Danieli Brolo Martins ${ }^{5}$

${ }^{1}$ Mestranda, Programa de Pós-graduação em Ciência Animal, Escola de Veterinária e Zootecnia, Universidade Federal de Goiás, Goiânia, Brasil. E-mail: evelyn oli18@hotmail.com

${ }^{2}$ Mestre e Residente de Patologia Clínica, Hospital Veterinário, Universidade Federal de Goiás, Goiânia, Brasil

${ }^{3}$ Médico Veterinário, Residente de Toxicologia, Hospital Veterinário, Universidade

Federal de Goiás, Goiânia, Brasil

${ }^{4}$ Graduando em Medicina Veterinária, Escola de Veterinária e Zootecnia da Universidade Federal de Goiás, Goiânia, Brasil

${ }^{5}$ Doutora, Docente do Programa de Pós-graduação em Ciência Animal, Escola de Veterinária e Zootecnia, Universidade Federal de Goiás, Goiânia, Brasil

Recebido em: 08/09/2015 - Aprovado em: 14/11/2015 - Publicado em: 01/12/2015 DOI: http://dx.doi.org/10.18677/Enciclopedia_Biosfera_2015_149

\section{RESUMO}

A eletroforese é uma técnica laboratorial simples que fraciona proteínas presentes em diversos tipos de fluido, levando em consideração suas cargas elétricas e/ou seu peso molecular. A técnica utiliza forças eletroforéticas e eletroendosmóticas, onde um pólo positivo (ânodo) e outro negativo (cátodo) geram um potencial elétrico, que promove a migração proteica, gerando diferentes bandas, representadas por albumina e globulinas alfa, beta e gama. Dois métodos de eletroforese são utilizados atualmente, sendo eles: a eletroforese convencional por zonas e a eletroforese capilar. No primeiro método, as proteínas migram através dos poros presentes em suportes como acetato de celulose, gel de agarose ou poliacrilamida, formando zonas de proteínas no eletroforetograma. Já no segundo, as proteínas são separadas pelo seu tamanho e por outras propriedades físico-químicas, através do fluxo em um tubo capilar. Na medicina veterinária, além de ser empregada na clínica, contribuindo com o diagnóstico e o prognóstico de várias doenças, a técnica tem sido utilizada em diversas outras áreas, apresentando ampla aplicabilidade em situações distintas. Desta forma, o objetivo do presente trabalho é apresentar uma breve revisão sobre a eletroforese de proteínas, destacando as principais técnicas existentes e proteínas fracionadas, além de sua aplicação e importância na medicina veterinária.

PALAVRAS-CHAVE: Fracionamento proteico, medicina veterinária, proteinograma. 


\title{
ELECTROPHORESIS: CONCEPTS AND APPLICATIONS
}

\begin{abstract}
Electrophoresis is a simple laboratory technique that fractionates proteins present in various types of fluid, taking into consideration its electrical cargo and / or its molecular weight. The technique uses electrophoretic and eletroendosmotic forces, where a positive pole (anode) and negative (cathode) generate an electrical potential, which promotes protein migration, generating different bands, represented by albumin and alpha, beta and gamma globulins. Two electrophoresis methods are currently used, namely: conventional electrophoresis by zone and capillary electrophoresis. In the first method, proteins migrate through the pores present in substrates such as cellulose acetate, agarose or polyacrylamide gel, proteins that perform zones in the electrophoretogram. In the second, proteins are separated by size and other physical and chemical properties, flow through a capillary tube. In veterinary medicine, in addition, it can be used in the clinic, contributing to the diagnosis and prognosis of various diseases. The technique has been used in several other areas, having broad applicability in different situations. Thus, the objective of this paper is to present a brief review of the protein electrophoresis, highlighting the main existing technical and fractionated proteins, as well as their application and importance in veterinary medicine.
\end{abstract}

KEYWORDS: Protein fractioning, proteinogram, veterinary medicine.

\section{INTRODUÇÃO}

As proteínas são macromoléculas orgânicas nitrogenadas, formadas por cadeias polipeptídicas de aminoácidos. Podem ser polares ou apolares, dependendo do $\mathrm{pH}$ da molécula, que é determinado pela distribuição elétrica resultante das ligações covalentes ou iônicas de seus grupos estruturais (ECKERSALL, 2008). A palavra proteína vem do grego "proteos", sugerida pelo químico holandês Mulder no século XIX, que significa o primeiro, por estar relacionada com a forma básica da estrutura corporal, já que é um componente universal de todos os tecidos, tanto vegetais quanto animais (HARPER et al., 1982; TORRES FILHO, 2008).

Os aminoácidos, unidade básica das proteínas, possuem uma estrutura em comum, constituída de um grupo amina, um grupo carboxil e um radical, chamado grupamento lateral. Este último fornece identidade ao aminoácido. As diferentes quantidades e combinações presentes em uma molécula de proteína, confere a ela peso e carga elétrica distinta (ECKERSALL, 2008).

Nesse sentido, a eletroforese é uma técnica laboratorial simples que utiliza a corrente elétrica para promover a separação de moléculas carregadas, como proteínas e ácidos nucleicos. A migração das partículas ocorre por diferença de carga elétrica e por peso molecular, de forma que moléculas menores migram mais rapidamente que as maiores. A eletroforese, que inicialmente era quase que exclusiva do meio científico, tem sido cada vez mais utilizada na rotina laboratorial por fornecer informações úteis sobre o estado geral do paciente, além de contribuir com diagnóstico e prognóstico de várias enfermidades, bem como, com 0 estadiamento das mesmas (MCPHERSON, 2011). Além de auxílio clínico, a eletroforese também é utilizada na indústria alimentícia colaborando com a detecção ENCICLOPÉDIA BIOSFERA, Centro Científico Conhecer - Goiânia, v.11 n.22; p. 1130 2015 
de adulteração e fraudes de alimentos de origem animal (SOUZA et al., 2000; EGITO et al., 2006; LEITE \& NICOLAU, 2006; DAGUER et al., 2010).

Com o passar dos anos, distintas técnicas para o fracionamento de proteínas foram desenvolvidas e melhoradas, facilitando o emprego em várias situações, permitindo com isso, a análise de múltiplos tipos de amostra. Atualmente, são conhecidos cinco tipos de eletroforese, cada qual com especificações e utilidades, mas todos com um bom desempenho no fracionamento de proteínas. Uma grande quantidade de proteínas são encontradas no soro, como anticorpos, enzimas, fatores de coagulação, carreadores de moléculas, e muitas outras. A análise das proporções dessas proteínas após o fracionamento oferece informações importantes sobre os aspectos fisiológicos, possibilitando a correlação diante de variações patológicas (VAVRICKA et al., 2009). Desta forma, o objetivo do presente trabalho é apresentar uma breve revisão sobre a eletroforese de proteínas, destacando as principais técnicas existentes e proteínas fracionadas, além da aplicação e importância na medicina veterinária.

\section{HISTÓRICO}

O termo proteína" origina-se da palavra grega "proteos", que significa "essencial" e foi utilizado pela primeira vez em 1839, quando Mulder notou que essa substância estava presente tanto na matéria animal quanto vegetal. Panum conseguiu em 1851 separar uma fração de proteína usando uma técnica de precipitação com ácido acético, que posteriormente, em 1862, foi denominada de "globulina" por Schimidt. Kuhne foi o primeiro cientista a conseguir separar duas frações proteicas, utilizando o anidro carbônico e o ácido acético para fazer a precipitação destas, intitulando as frações de "paraglobulina" e "alcalialbuminato", respectivamente. Estas foram denominadas, em seguida, de "seroglobulina", por Weil e Hynius. No final do século XIX, Mehu, um químico francês, desenvolveu alguns métodos para a medição dos componentes proteicos no sangue. Ele publicou em 1878, um método para quantificar o que chamou de albumina ou albuminoides (TORRES FILHO, 2008).

Os fundamentos da eletroforese têm origem nos estudos de Michaelis, no ano de 1909, quando este percebeu que proteínas se moviam quando submetidas a um campo elétrico, podendo ser separadas em frações. Por anos, alguns cientistas como Sverdberg e Scott (1924), Sverdberg e Tiselius (1926) e Theorell (1935) trabalharam para aperfeiçoar a técnica (BURTIS \& ASHWOOD, 2001). Entretanto, a base para a eletroforese de proteínas utilizada nos dias de hoje foi fundamentada em um método desenvolvido em 1937 pelo bioquímico sueco Arne Tiselius, ganhador do prêmio Nobel. Seu trabalho científico relatava o fracionamento das proteínas séricas por eletroforese, realizada na época em equipamentos similares aos de baterias de automóveis, onde as separações das frações ocorriam em meio líquido. Esse tipo de eletroforese foi denominada de "eletroforese de fase líquida" e foi introduzida como meio de auxílio ao diagnóstico clínico. Porém, por ser de aplicação difícil e onerosa, ficou restrita a área científica em apenas algumas instituições de pesquisas (TISELIUS, 1937).

Em 1949, Linus Pauling e colaboradores publicaram na revista Science o fracionamento eletroforético da hemoglobina $S$ usando a eletroforese em papel filtro. Apesar de precisar de 12 a 18 horas para fracionar proteínas, essa técnica foi empregada no uso laboratorial para análises específicas nos estudos de proteínas ENCICLOPÉDIA BIOSFERA, Centro Científico Conhecer - Goiânia, v.11 n.22; p. 1131 
séricas, lipoproteínas e hemoglobinas (PAULING et al., 1949). Entretanto, a técnica tinha a desvantagem de ter baixa reprodutibilidade. Somava-se a isso que o papel utilizado, por não ser transparente, dificultava a quantificação das frações proteicas (LANDERS, 2008).

Um modelo revolucionário para a época foi desenvolvido pelos imunologistas franceses Curtis Willians e Pierre Grabar, em 1953. A técnica permitia a separação das frações proteicas a partir da precipitação dos anticorpos. Foi nomeada de imunoeletroforese e destacava-se das outras técnicas por utilizar uma fina película de gel de ágar espalhado sobre lâminas de vidro como suporte. Esse método foi aperfeiçoado para outros tipos de proteínas como enzimas, lipoproteínas e hemoglobinas, permitindo à quantificação por densitometria, apresentando excelente reprodutibilidade e sensibilidade, além de um curto tempo de quatro horas para a corrida eletroforética. Entretanto, problemas com o grau de impureza do gel de agarose estavam interferindo nos resultados. Este fato possibilitou, a partir de 1970, a padronização de métodos industriais para a purificação do gel de agarose (NAOUM, 2012).

A descoberta do gel de agarose proporcionou avanços da técnica de eletroforese. Vários tipos de amostras como soro, plasma, líquor ou hemolisado de hemoglobinas eram utilizados para o exame, e isso no mesmo suporte de gel, o que tornava a técnica mais prática e viável na rotina laboratorial. A avaliação quantitativa das frações foi favorecida com o desenvolvimento desta técnica e o uso de densitômetro. A utilização do gel de agarose estimulou ainda a elaboração de outros tipos de géis, como o gel de amido (1955) e o de acrilamida (1959). Destes, apenas o gel de acrilamida foi adaptado e melhorado. O gel de amido caiu em desuso por dificultar a corrida eletroforética, já que levava cerca de 15 horas, além de necessitar de refrigeração (JEPPSON et al., 1979).

A partir do gel de acrilamida foi desenvolvido o gel de poliacrilamida, que nada mais é que uma polimerização vinílica da acrilamida e da bisacrilamida. $O$ resultado dessa reação é um gel com características físicas ideais para uma eletroforese altamente seletiva, como densidade, elasticidade, transparência e tamanho dos poros. Mesmo apresentando esse alto grau de resolução, o uso dessa técnica é economicamente dispendioso para a rotina de análises de amostras, sendo mais utilizado em pesquisas científicas (NAOUM, 2012).

Graham e Grunbaum, buscando desenvolver técnicas mais práticas para a realização da eletroforese na rotina laboratorial criaram, em 1963, o método para fracionamento de proteínas e enzimas utilizando como suporte o acetato de celulose. Tal técnica obteve êxito no meio científico por ser simples, barata e por permitir excelente grau de separação e quantificação das frações proteicas. O suporte de celulose foi melhorado, tendo os poros gelatinizados, ficando conhecido como celogel (RICHES \& KOHN, 1987).

No início da década de 1960 outra técnica de eletroforese foi desenvolvida usando o gel de ágar ou poliacrilamida e uma sustância chamada de anfólito. Esse novo produto misturado ao gel produzia um gradiente de $\mathrm{pH}$ entre os pólos positivo e negativo, criando faixas milimétricas de $\mathrm{pH}$ em ordem crescente. Ao se aplicar amostras que contém diferentes proteínas com pHs específicos nesse gel, há uma reação entre estas proteínas com o correspondente anfotérico, levando a precipitação. Tal método recebeu o nome de eletroforese de isofocalização, e tem sido empregada em pesquisas e rotina laboratorial por apresentar alto grau de resolução no fracionamento proteico (NAOUM, 2012). 
Uma das últimas técnicas a ser desenvolvida foi a técnica de eletroforese capilar, em 1986, por Lauer e Mc Manigill, onde uma corrente eletrosmótica é criada dentro de um tubo capilar conectado a dois reservatórios contendo solução tampão, onde um representa o ânodo e o outro o cátodo. Sob ação de corrente elétrica a amostra se movimenta no interior do tubo, onde há interação das cargas elétricas das proteínas da amostra com os íons da solução tampão. Tal processo promove o fracionamento proteico, formando, dentro do tubo, pequenas micelas, posteriormente identificadas por um detector específico que registra em gráficos a posição e a concentração de cada proteína. Essa técnica tem uma vasta aplicação, por fracionar desde moléculas pequenas até as mais volumosas e complexas, como proteínas e ácidos nucleicos, de forma rápida e eficiente (SPUDEIT et al., 2012).

\section{DEFINIÇÃO}

O termo eletroforese é usado para descrever a migração de uma partícula carregada sob influência de um campo elétrico, permitindo a separação dos diferentes tipos de proteínas séricas ou plasmáticas, determinando as proporções relativas. Sob condições de corrente elétrica constante, a força de deslocamento de uma partícula é resultado da carga efetiva, da molaridade do tampão e da resistência do meio usado como suporte (ágar, acetato, gel capilar). Como as proteínas possuem cargas positivas e negativas, a mobilidade eletroforética é diretamente proporcional à carga da partícula e inversamente proporcional à viscosidade do meio (ECKERSALL, 2008).

A técnica de separação de proteínas utiliza forças eletroforéticas e eletroendosmóticas, onde um pólo positivo (ânodo) e outro negativo (cátodo) geram um potencial elétrico. Este potencial promove a migração das proteínas em direção ao ânodo e, dependendo do peso molecular e da carga elétrica, percorrem distâncias distintas, gerando diferentes bandas, representadas por albumina, globulinas alfa e beta e gama. As frações separadas são observadas a partir de um corante sensível a proteínas e quantificadas por densitometria ou eluição. Os resultados são expressos em percentagem de concentração das diversas frações e em forma gráfica. A taxa de migração das proteínas pode ser afetada pelo $\mathrm{pH}$, força iônica e composição do sistema tampão usado (MCPHERSON, 2011).

No momento, existem dois métodos para a realização da eletroforese. $\mathrm{Na}$ eletroforese convencional por zonas as proteínas migram através dos poros presentes em suportes como acetato de celulose, gel de agarose ou poliacrilamida, formando zonas de proteínas no eletroforetograma. Já na eletroforese capilar as proteínas são separadas pelo tamanho e por outras propriedades físico-químicas, através do fluxo em um tubo capilar. Por apresentar alta resolução esse método permite a separação de bandas poucos visíveis nos outros métodos, resultando em um padrão de seis bandas proteicas (TORRES FILHO, 2008).

\section{PRINCÍPIOS FÍSICO-QUÍMICOS DA ELETROFORESE}

A eletroforese consiste em empregar uma corrente elétrica contínua para separar os componentes do sangue, urina, líquor e outras soluções. Quanto maior a corrente, maior será a velocidade com que as moléculas de proteínas se moverão, já que os aminoácidos que as compõem possuem em sua composição cargas elétricas positivas ou negativas. Dessa maneira, as moléculas com carga negativa migram para o pólo positivo, as moléculas com carga positiva migram para o pólo negativo e as que apresentam cargas elétricas equilibradas permanecerão estáticas. As ENCICLOPÉDIA BIOSFERA, Centro Científico Conhecer - Goiânia, v. 11 n.22; p. 1133 2015 
proteínas de menor peso molecular irão migrar mais rapidamente que as de maior peso (O'CONNELL et al., 2005).

Para a realização dessa técnica, é necessário um conjunto de sistemas formado por um suporte de fracionamento, uma cuba de eletroforese, uma fonte de voltagem e uma solução tampão. O suporte pode ser de acetato de celulose, gel de agarose ou poliacrilamida e tubos capilares. A cuba é um equipamento formado por dois compartimentos preenchidos com solução tampão, formando os eletrodos, sendo um positivo e o outro negativo. A fonte de voltagem é um aparelho que transforma a corrente alternada em contínua, podendo ter a intensidade regulada. É essa fonte que determina a polaridade dos compartimentos da cuba. A solução tampão é formada por água, sal ácido e sal básico. Tal solução pode ser ácida ou alcalina, sendo específica para cada tipo de eletroforese, dada pelo grau de molaridade ou força iônica da solução (NAOUM, 2012).

A maioria dos aminoácidos apresentam um ponto isoelétrico quase neutro. Entretanto, os polímeros que se ligam a esses aminoácidos os transformam em moléculas carregadas negativamente. Por isso, a maioria das soluções tampões utilizadas no sistema eletroforético são alcalinas. Como as proteínas são estruturas com diferentes graus de complexidade, o método para fracionamento eletroforético destas não é o mesmo. Para tal, existem soluções tampões específicas para cada tipo de proteína, que são agrupadas, segundo a disposição espacial, em estruturas primária, secundária, terciária e quaternária (MCPHERSON, 2011).

A eletroforese movimenta íons através de um suporte estabelecido. A troca iônica entre as partículas proteicas e os grupos eletricamente carregados que compõe o suporte geram um movimento elétrico de baixa intensidade em direção oposta ao sentido da eletroforese. Esse movimento intrínseco é denominado eletroendosmose. Esse fenômeno atrasa o desenvolvimento eletroforético, elevando a intensidade de calor da eletroforese. No suporte de celulose, esta é desprezível. Contudo, nos suportes de ágar e poliacrilamida, a eletroendosmose tem importância significativa e está diretamente ligada a pureza e qualidade do gel, bem como, da sua espessura. Quanto mais puro e menos ionizável o gel, menor será o efeito eletroendosmótico e quanto mais espesso o gel maior será a eletroendosmose (NAOUM, 2012).

\section{COMPONENTES PROTEICOS DA ELETROFORESE E SEU SIGNIFICADO CLÍNICO}

Atualmente cerca de 70 tipos diferentes de proteínas plasmáticas, das 289 relatadas em humanos, já foram identificadas e validadas com o auxílio de técnicas aprimoradas e de alta sensibilidade. Contudo, os métodos eletroforéticos disponíveis na rotina laboratorial veterinária para a investigação clínica possibilitam o fracionamento de quatro a seis frações proteicas, sendo albumina e globulinas, alfa (1 e 2), beta (1 e 2) e gama (ECKERSALL, 2008) (Tabela 1). O suporte utilizado para o fracionamento proteico de soro de animais domésticos influencia na quantidade de proteínas isoladas. O suporte de acetato de celulose segrega de cinco a nove regiões de proteínas, enquanto que o gel de agarose separa de 10 a 15 proteínas. As bandas correspondentes às globulinas também apresentam diferenças entre as espécies, quanto ao fracionamento. A separação de proteínas do soro de cães, gatos e equinos, realizada no suporte de acetato de celulose, origina cinco zonas de globulinas, sendo: alfa-1, alfa-2, beta-1, beta-2 e gama. Já no soro de ENCICLOPÉDIA BIOSFERA, Centro Científico Conhecer - Goiânia, v.11 n.22; p. 1134 
bovinos, as globulinas são comumente encontradas em três zonas: alfa, beta e gama (STOCKHAM \& SCOTT, 2011).

As concentrações proteicas podem apresentar alterações durante processos inflamatórios e/ou infecciosos, sendo classificadas em três grupos distintos: proteínas de fase aguda positiva, proteínas de fase aguda negativa e proteínas de resposta tardia. Processos inflamatórios agudos promovem uma resposta sistêmica, ativando as proteínas de fase aguda (PFA). Tais proteínas vêm sendo utilizadas como biomarcadores de inflamação, já que os níveis séricos apresentam variação por estimulação dos hepatócitos pelas citocinas. As PFA positivas exibem concentrações séricas aumentadas, enquanto que as PFA negativas demonstram concentrações diminuídas. Ainda, as PFA de resposta tardia aumentam a concentração dias depois do início da inflamação (ECKERSALL, 2008; STOCKHAM \& SCOTT, 2011).

TABELA 1 - Principais proteínas séricas presentes nas zonas eletroforéticas.

\section{Zonas Componentes proteicos}

\begin{tabular}{ll}
\hline Albumina & Pré-albumina e albumina \\
Alfa-1 & $\begin{array}{l}\text { Alfa-1 glicoproteína ácida, alfa-1 antitripsina, alfalipoproteína, alfa-1 } \\
\text { antiquimotripsina }\end{array}$ \\
Alfa-2 & Alfa-2 macroglobulina, haptoglobina, ceruloplasmina, \\
Beta-1 & Transferrina \\
Beta - 2 & Complemento C3, beta lipoproteína, proteína C reativa \\
Gama & $\operatorname{lgG}, \operatorname{lgE}, \operatorname{lgM}, \lg A$
\end{tabular}

Fonte: ECKERSALL, 2008.

\section{Pré-Albumina}

A pré-albumina ou transtiretina é uma proteína plasmática não glicosilada, presente no citoplasma dos hepatócitos e na circulação sob forma de proteína fixadora de retinol e pré-albumina propriamente dita. Apenas 10\% da pré-albumina transporta hormônios tireoidianos, podendo também ser saturada com a proteína fixadora de retinol e com a vitamina A. É sintetizada principalmente pelo fígado e em menor quantidade pelo plexo coroidal, sendo parcialmente catabolizada pelos rins. Entretanto, a eletroforese de rotina não detecta essa proteína no soro de mamíferos. Já em aves e répteis, essa proteína é detectada na eletroforese, migrando mais rapidamente que a albumina, aparecendo do lado esquerdo da zona correspondente à albumina (STOCKHAM \& SCOTT, 2011; JOHNSON et al., 2007).

\section{Albumina}

A albumina é a proteína mais abundante no organismo, correspondendo a $60 \%$ da concentração total de proteínas. É sintetizada pelos ribossomos no citoplasma de hepatócitos, transferida para o retículo endoplasmático rugoso, retículo endoplasmático liso e complexo de Golgi, através da membrana dos sinusóides. De toda albumina produzida pelo fígado, apenas $40 \%$ encontra-se no sangue e o restante, no espaço intersticial. Aproximadamente $60 \%$ da albumina é metabolizada nos músculos, fígado e rins. Por ser uma das menores moléculas 
proteicas é a primeira proteína a se perder na urina sempre que ocorre dano aos glomérulos renais (PRINSEN \& SAINT-VAN DER VELDEN, 2004).

Essa proteína desempenha funções importantes como transporte de diversas substâncias, tais como: hormônios, ácidos graxos livres, metais, aminoácidos e bilirrubina, além da manutenção da pressão oncótica. A união da albumina com algumas substâncias modifica a carga elétrica, alterando o traçado eletroforético, que aparece mais alongado, em direção ao ânodo. A análise quantitativa tem importante significado clínico, já que a diminuição pode indicar desde uma síntese hepática prejudicada, nos casos de hepatopatias crônicas, até perda renal, na síndrome nefrótica; intestinal, na enteropatia protideodispersivas; e cutânea, nos casos de queimaduras extensas. Outras situações que podem levar a diminuição da albumina incluem processos inflamatórios agudos, onde outras PFA aumentam, estimulando o contrabalanço proteico. Outras situações como subnutrição, má absorção e caquexia neoplásica também interferem no decréscimo desta proteína (TORRES FILHO, 2008).

\section{Alfa-1-Globulina}

As proteínas da fração alfa, na maioria das espécies, exceto nos ruminantes, são as globulinas que migram mais rapidamente na eletroforese, subdividindo-se em porção alfa-1 e porção alfa-2. Na zona de alfa-1 concentram-se as alfalipoproteínas, conhecidas como lipoproteínas de alta densidade (HDL). Já na região de alfa-2 a concentração proteica é de pré-betalipoproteínas, consideradas como sendo de densidade muito baixa (VLDL) e haptoglobinas. A região alfa-1 é composta por quatro proteínas específicas, entretanto a proteína mais importante e responsável por evidenciar essa zona na eletroforese é a alfa-1-antitripsina. Geralmente há aumento dessa fração em processos inflamatórios, infecciosos e imunes, de forma inespecífica (ECKERSALL, 2008).

\section{a) Alfa-1 Antitripsina}

Esta proteína é a mais abundante da fração alfa-1, correspondendo a $90 \%$ do pico normal e desempenha importante papel como inibidor de proteases, por neutralizar as atividades das enzimas proteolíticas tanto de origem bacteriana quanto leucocitária. É sintetizada em resposta a processos inflamatórios agudos, sendo por isso um importante marcador de fase aguda, além de ser relatada em cães com diversas neoplasias. $O$ aumento da alfa-1-antitripsina é particularmente característico das hepatopatias crônicas e agudas (CÉRON et al., 2005).

\section{b) Alfa-1 Glicoproteína Ácida}

Outra globulina de particular interesse clínico é a alfa-1-glicoproteína ácida, principal constituinte das mucoproteínas. É sintetizada nos hepatócitos e é caracterizada como uma proteína de fase aguda, não específica, que sofre aumento considerável durante processos inflamatórios agudos. Um estudo com cães infectados com parvovirose demonstrou um pico de elevação sérica dessa proteína no terceiro dia de infecção, permanecendo elevada por até 12 dias (KOGIKA et al, 2003). Níveis elevados desta proteína são observados em processos inflamatórios, neoplasias e terapia com corticoides. Todavia, o aumento não contribui para elevar o nível quantitativo da zona alfa-1(ISRAILI \& DAYTON, 2001). 


\section{Alfa-2 Globulina}

A zona alfa-2 é composta por várias proteínas, entre elas a haptoglobina, a alfa-2-macroglobulina e a ceruloplasmina. Assim como as alfa-1-globulinas, estas proteínas apresentam concentração sérica aumentada na presença de processos inflamatórios, infecciosos ou imunes, sendo classificadas como PFA. A alfa-2macroglobulina e a haptoglobina correspondem à maior parte dessa zona eletroforética, contudo, a haptoglobina move-se mais lentamente, devido à sua heterogeneidade molecular (SILVA et al., 2008).

Sob o ponto de vista clínico, a haptoglobina é a mais utilizada, por apresentar funções conhecidas e específicas, aumentando consideravelmente no curso dos processos inflamatórios agudos. Entretanto, o aumento da globulina alfa-2 macroglobulina, em torno de 10 vezes ou mais, ocorre na síndrome nefrótica, quando outras proteínas de peso molecular mais baixo já foram perdidas (KOGIKA et al., 2003).

\section{a) Haptoglobina}

A haptoglobina é uma glicoproteína produzida principalmente pelos hepatócitos, mas também por outros tecidos como rins, pulmões e pele. Desempenham funções como atividade anti-inflamatória, agente bacteriostático, antioxidante celular e facilitadora da atividade dos macrófagos. Em casos de hemólise intravascular, como ocorre em doenças como a hemoparasitose por Babesia spp. em cães, equinos e ruminantes, a haptoglobina se liga à hemoglobina livre, formando um complexo proteico, impedindo a ação tóxica da hemoglobina nos túbulos renais, além de reter o ferro, dificultando o crescimento bacteriano. Posteriormente, as células do sistema monocítico fagocitário removem esse complexo haptoglobina-hemoglobina da circulação. Portanto, em casos de síndromes hemolíticas, há marcante diminuição das haptoglobinas, sendo um sensível marcador do índice de hemólise (YANG et al., 2003).

A haptoglobina é uma das principais PFA positiva na maioria dos animais, especialmente nos bovinos, que em condições normais, apresentam níveis muito baixos. Porém, processos inflamatórios e infecciosos elevam a concentração plasmática desta, permitindo sua detecção (ECKERSALL, 2008). Em cães, a haptoglobina é particularmente sensível a glicocorticosteróides, e o nível pode estar elevado após o tratamento com esse tipo de fármaco e em casos de hiperadrenocorticismo (MARTíNEZ-SUBIELA et al., 2001). Além desses casos, a elevação sérica da haptoglobina nessa espécie está relacionada à hepatite crônica e aguda, doenças inflamatórias, neoplásicas e autoimunes (MCGROTTY et al., 2003; PLANELLAS et al., 2009).

\section{b) Ceruloplasmina}

A ceruloplasmina é uma glicoproteína alfa-2 de fase aguda positiva moderada, e apresenta os níveis séricos aumentados nos processos inflamatórios, infecciosos, virais e parasitários. É a principal proteína responsável pelo transporte do cobre sérico, utilizado na eritropoiese e como antioxidante tecidual, protegendo os tecidos do oxigênio tóxico oriundo da fagocitose de micro-organismos, nos processos inflamatórios. A ceruloplasmina desempenha ainda atividade de ferroxidase, auxiliando na oxidação do ferro da forma ferrosa para férrica. Apresenta meia vida de aproximadamente quatro dias (CÉRON \& MARTíNEZSUBIELA, 2004). 
Em cães, o aumento está relacionado com processos inflamatórios e lesões teciduais, sendo mais sensível que o fibrinogênio plasmático e a contagem total de leucócitos, e menos sensível somente que a haptoglobina. O decréscimo desta é notado ao nascimento, em casos de desnutrição ou deficiência na absorção de nutrientes, nefrose e moléstias hepáticas associadas à intoxicação de cobre (CÉRON et al., 2010). Processos inflamatórios leves em ruminantes, equinos e suínos elevam a concentração da ceruloplasmina (MARTíNEZ-SUBIELA et al., 2001). Nos bovinos o decréscimo está associado à deficiência de cobre na alimentação (BORGES et al., 2005).

\section{Beta Globulinas}

As beta globulinas são compostas por um grupo heterogêneo de proteínas, das quais as principais são: betalipoproteínas, transferrina e complemento C3. $\mathrm{Na}$ eletroforese as beta globulinas são fracionadas em beta-1 e beta-2, na maioria dos animais domésticos, exceto nos ruminantes. Eletroforeses realizadas com acetato de celulose evidenciam as proteínas transferrina e o componente C-3 do sistema de complemento no traçado eletroforético. A separação nítida destas é possível com a adição de cálcio à solução tampão. Esse suporte não permite a revelação de outras proteínas como as betalipoproteínas, por falta de afinidade com os corantes proteicos utilizados e pela dispersão que ocorre durante a migração (SILVA et al., 2008).

\section{a) Transferrina}

A transferrina é uma glicoproteína sintetizada pelos hepatócitos cuja principal função é o transporte do ferro plasmático, atuando na absorção intestinal e distribuição orgânica deste, sendo a única proteína transportadora de íons (CÉRON et al., 2005). Apresenta uma importante atividade antibacteriana por indisponibilizar o ferro para as bactérias durante o processo inflamatório. Durante um processo inflamatório ou nos casos de anemia proveniente de doença crônica, os níveis séricos desta proteína tendem a diminuir, caracterizando-a como uma PFA negativa. A deficiência de ferro pode acarretar anemia ferropriva, elevando os níveis séricos dessa proteína. A quantificação sérica da transferrina é utilizada principalmente para avaliar o metabolismo do ferro no organismo dos animais (TIZARD, 2008).

\section{b) Proteína C Reativa}

É uma PFA produzida pelo fígado após estímulo de citocinas inflamatórias. Ainda que não seja uma imunoglobulina, encontra-se na zona das beta globulinas, sendo raramente observada em soro de mamíferos na eletroforese de rotina (MEYER \& HARVEY, 2004; STOCKHAM \& SCOTT, 2011). É utilizada com um marcador muito sensível de processos inflamatórios agudos, principalmente em cães e suínos, por apresentarem aumento sérico desta antes mesmo de uma resposta leucocitária (ECKERSALL \& BELL, 2010). Em bovinos essa resposta não é tão rápida, e o aumento pode ser observado no leite de vacas com mastite, não sendo um bom marcador sistêmico de fase aguda nessa espécie. Nos equinos a elevação sérica foi ressaltada em animais com artrite, pneumonia e após castração (MARTÍNEZ-SUBIELA et al., 2001).

\section{Gamaglobulinas}

É a zona que engloba todas as classes de imunoglobulinas, distribuídas em ENCICLOPÉDIA BIOSFERA, Centro Científico Conhecer - Goiânia, v.11 n.22; p. 1138 2015 
duas regiões distintas, gama-1 e gama-2, na eletroforese. As imunoglobulinas IgA, $\lg M$ e $\lg E$ são encontradas primariamente na região gama-1 e a $\lg G$, que é a globulina que mais se destaca, na região gama-2. Apesar da heterogeneidade molecular das imunoglobulinas, a migração destas ocorre de forma homogênea, originando uma banda compacta e bem delimitada, denominada de banda policlonal. Entretanto, algumas gamopatias monoclonais podem originar um traçado eletroforético distinto, ocupando uma posição ampla e delimitada (BUSH, 2004).

De forma geral, as gamaglobulinas aumentam nos casos de inflamação crônica. Entretanto, existem situações específicas que favorecem o aumento de uma única gamaglobulina, como nos casos de alergia, onde os níveis de IgE apresentamse elevados. Como a IgG é a imunoglobulina mais evidente no traçado, o aumento está relacionado com doenças infecciosas, doenças do tecido conjuntivo, doenças hepáticas, mielomas e outros tumores do sistema retículo endotelial (TIZARD, 2008). A diferença de concentração proteica em situações distintas é evidente no traçado eletroforético (Figura 1), confirmando a eficiência da técnica na avaliação geral do animal, além do diagnóstico de diversas doenças.

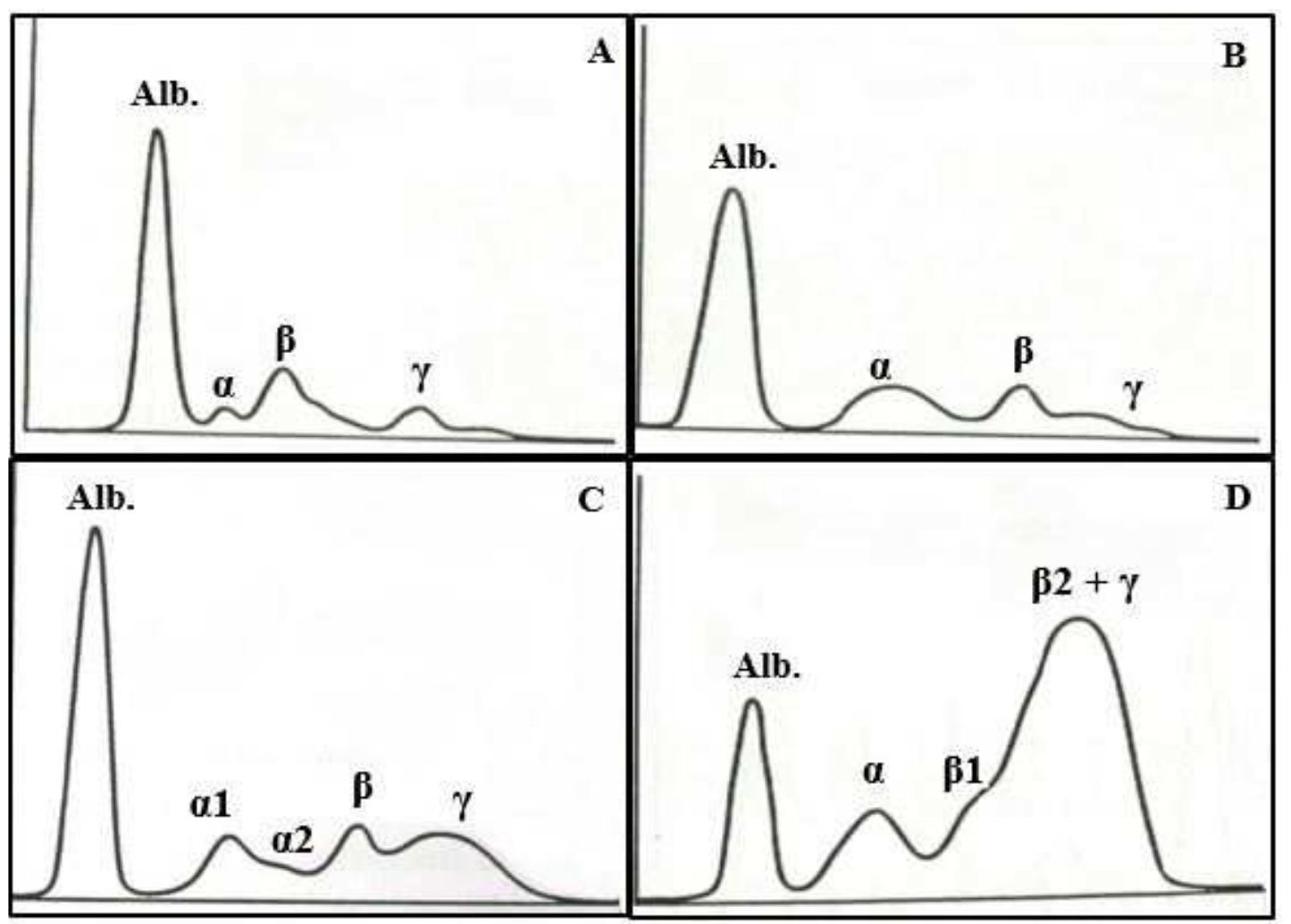

FIGURA 1: Gráficos de eletroforese em acetato de celulose realizado com soro de bovinos, demonstrando o fracionamento de proteínas em algumas situações específicas. A: Eletroforese realizada em um bezerro recém-nascido que ainda não ingeriu o colostro; B: Eletroforese realizada em um bezerro de seis semanas; C: Eletroforese de um bovino adulto e hígido; D: Eletroforese de um bovino com abcesso hepático crônico.

Fonte: Adaptado de KANEKO, 1997. 


\section{TIPOS DE ELETROFORESE}

\section{Acetato de Celulose}

O acetato de celulose é o produto de uma reação da celulose com anidrido acético e ácido acético, utilizando como catalisador o ácido sulfúrico. O pesquisador J. Kohn, em 1958, utilizou esse meio para separação e fracionamento de proteínas séricas e observou que o mesmo apresentava algumas características físicoquímicas que facilitavam a corrida eletroforética. Vantagens como material neutro, absorção uniforme das proteínas, microporos homogêneos, formação de filmes transparentes que facilitam a leitura, boas condições de armazenamento por longo período e baixo custo tornam esse meio ideal para uso na rotina laboratorial. Permite o fracionamento de proteínas, lipoproteínas, hemoglobinas e substâncias com baixo peso molecular como aminoácidos, peptídeos e nucleotídeos (NAOUM, 2012).

Esse suporte além de permitir uma separação proteica rápida e possibilidade de armazenamento prolongado dos filmes corados, apresenta a vantagem ter um custo relativamente baixo, sendo a técnica mais facilmente disponível na rotina laboratorial. Contudo, o fracionamento proteico é limitado, por separar apenas cinco a sete grupos de proteína. Na medicina veterinária esse suporte foi amplamente utilizado (HAGIWARA \& GERMANO, 1974; FAGLIARI et al., 1998; BORGES et al., 2001), porém, com desenvolvimento de novas técnicas que permitem principalmente uma separação proteica de alta resolução, essa técnica caiu em desuso.

\section{Gel de Ágar}

O gel de agarose é um polissacarídeo linear não absorvível, não fermentável e atóxico, extraído de diversos gêneros de algas marinhas. Apresenta em sua composição diversas substâncias como fibras, sais minerais e proteínas, que podem interferir na migração proteica, principalmente pelo efeito eletroendosmótico. Por isso, a pureza do ágar utilizado é que vai determinar o sucesso do fracionamento das proteínas (NAOUM, 2012).

Apresenta ampla capacidade de separação de proteínas, por permitir às proteínas de alto peso molecular, movimentação livre, conforme sua carga, produzindo resultado melhor que o suporte de acetato de celulose. $\mathrm{O}$ gel pode ser facilmente preparado no laboratório, tornando a técnica prática e de baixo custo. A concentração da agarose varia de 0,5 a $2 \%$, e é o que determina o tamanho do poro do gel, de forma que quanto mais concentrado for a agarose, menor serão os poros do gel. É utilizado tanto na rotina laboratorial quanto em pesquisas científicas (AZEVEDO, 2003).

Apesar de fracionar as proteínas em apenas cinco a sete regiões, como o acetato de celulose, essa é a técnica mais utilizada na rotina laboratorial veterinária, por apresentar algumas vantagens. Dentre estas, destacam-se a possibilidade de a técnica ser automatizada, o que facilita e agiliza a execução; o tamanho variável dos poros, permitindo a separação de diversos tipos de moléculas, desde lipoproteínas à ácidos nucleicos; e a qualidade da resolução do fracionamento proteico é melhor. A principal desvantagem da eletroforese em gel de agarose é a fragilidade do filme utilizado, necessitando de equipamento caro a fim de preservá-lo (CÉRON et al., 2010).

\section{Gel de Poliacrilamida}

O gel de poliacrilamida foi utilizado como meio eletroforético em 1959 por Raymond e Weintraub para fracionamento de macromoléculas. O gel é formado por 
um processo de polimerização vinílica da acrilamida, um monômero, e da bisacrilamida, tendo a participação de catalizadores, como a riboflavina ou 0 persulfato de amônio. A porosidade do gel formado pode ser determinada pela concentração da acrilamida, de forma que quanto maior a concentração desta, menores serão os poros do gel (NAOUM, 2012).

Esse suporte permite o fracionamento proteico tanto pelo sistema nativo, que separa as proteínas levando em consideração apenas as cargas elétricas (PAGE), quanto pelo sistema desnaturante, que solubiliza as proteínas em um tampão contendo um reagente desnaturante, sendo o SDS (dodecil sulfato de sódio) - mais empregado. Para isso, a preparação do gel de poliacrilamida pode ser individualizada para diferentes faixas de peso molecular de substâncias que serão processadas, levando em consideração a concentração do gel, já que poros menores permitem a passagem de proteínas menores. O detergente aniônico (SDS) interage com as cadeias peptídicas das proteínas, promovendo a desnaturação destas, que ficam com cargas negativa. Assim, a separação ocorre apenas pela diferença de peso molecular, caracterizando a técnica conhecida como SDS-PAGE (ECKERSALL, 2008).

Quando comparada com as demais técnicas, a eletroforese em gel de poliacrilamida é a que apresenta melhor resultado pois possibilita a visualização de proteínas com concentrações séricas baixas e identificação de 15 a 20 proteínas. Apesar disso, o emprego dessa técnica na rotina laboratorial torna-se inviável devido à dificuldade de execução da mesma, limitando-se a casos específicos e pesquisas científicas (RADKTE, 2003).

\section{Focalização Isoelétrica}

Esse tipo de eletroforese é usado especificamente para o fracionamento de substâncias moleculares, como proteínas e DNA, somente por suas cargas elétricas, permitindo que cada proteína migre para o ponto isoelétrico, concentrando-se nas zonas em que alcançam a posição do pH específico. Este método caracteriza-se pelo uso de um suporte de gel (ágar ou poliacrilamida) que tenha, adicionado em sua composição, substâncias anfotéricas, distribuídas em faixas com $\mathrm{pH}$ graduais dispostas em zonas estabelecidas entre o ânodo e cátodo (NAOUM, 2012).

Após alguns ajustes desde a criação, a eletroforese por focalização isoelétrica apresenta uma qualidade de fracionamento proteico superior a qualquer outro tipo de eletroforese. Porém, o alto custo dos materiais e a necessidade de pessoal especializado para a execução e interpretação, torna o uso da técnica apropriado apenas em pesquisas científicas. É mais indicada para rastreamento de hemoglobinopatias (BERTHOLO \& MOREIRA, 2006).

\section{Eletroforese Capilar}

A eletroforese capilar é uma técnica que se difere das demais por ser a única capaz de separar macromoléculas carregadas, utilizando vários métodos de separação, como a eletroforese capilar de zona, isotacoforese capilar e eletroforese capilar em gel. Além de proteínas séricas, essa técnica permite a determinação de várias outras substâncias, como hidrocarbonetos, vitaminas, fármacos e ácidos orgânicos (MICKE, 2004).

Dos vários métodos existentes na eletroforese capilar para separação de proteínas, a técnica mais utilizada é a eletroforese capilar de zona, por ser simples e rápida. O fracionamento ocorre pela diferença das velocidades dos íons no campo ENCICLOPÉDIA BIOSFERA, Centro Científico Conhecer - Goiânia, v.11 n.22; p. 1141 
elétrico formado no tubo capilar, que está preenchido com uma solução tampão. Ao se introduzir a amostra na extremidade positiva (ânodo) do tubo, a diferença de potencial aplicada faz com que os íons da amostra migrem através do tubo, com velocidades e sentidos variados. A análise qualitativa baseia-se na comparação dos tempos de migração da solução padrão com os tempos de migração das substâncias da amostra avaliada. A análise quantitativa é expressa em gráficos que expressam os picos de cada fração separada (SPUDEIT et al., 2012).

O uso da eletroforese capilar ainda é restrito já que o equipamento utilizado nessa técnica tem um custo elevado. Contudo, é uma ótima alternativa para fracionamento de proteínas, por ser rápida (apenas quatro minutos), por oferecer boa resolução e eficiência, além de necessitar de uma pequena quantidade de amostra. Se a técnica for toda automatizada, a produtividade aumenta consideravelmente, diminuindo o uso de reagentes, gerando baixo custo analítico (CRIVELLENTE et al., 2008). É frequentemente utilizada na análise dos íons presentes nos alimentos de origem animal, compostos e fluídos biológicos (MENDES, 2010).

\section{ELETROFORESE NA VETERINÁRIA}

A eletroforese das proteínas séricas é um importante método para quantificação de proteínas presentes em diversos tipos de amostras, com o objetivo de auxiliar no diagnóstico, prognóstico e curso de diversas doenças. Na medicina veterinária, várias técnicas têm sido empregadas, sendo as mais utilizadas a eletroforese em acetato de celulose, em gel de agarose e em gel de poliacrilamida, permitindo a visualização de cinco a sete bandas proteicas. A aplicabilidade dessas técnicas visa fornecer informações importantes sobre vários aspectos (ECKERSALL, 2008).

$\mathrm{Na}$ década de 1950, a eletroforese já era utilizada para identificar e padronizar as proteínas presentes no plasma seminal de bovinos, a fim de relacionar os achados com a fertilidade dos animais e avaliar as proteínas após congelamento do sêmen (JOBIM et al., 2003; CASTRO et al., 2004). Vários meios têm sido utilizados, desde o gel de amido, passando pelo acetato de celulose e gel de poliacrilamida, sendo este último o mais utilizado e recomendado (TEIXEIRA et al., 2009).

Geralmente, a eletroforese é realizada como exame de triagem, sendo uma importante ferramenta na clínica veterinária, por fornecer informações relevantes sobre o estado geral dos animais, bem como uma avaliação sistêmica frente a algum processo inflamatório ou infeccioso. Alguns trabalhos comparam a eletroforese das proteínas séricas de animais saudáveis e animais com doenças específicas, analisando quais as principais alterações no traçado eletroforético, constatando a maneira como o organismo responde à injúria (VIEIRA, 2009; FRANÇA et al., 2011; GEROU-FERRIANI et al., 2011).

O uso da eletroforese no universo científico veterinário tem aumentado consideravelmente, não apenas por fornecer informações específicas, mas por colaborar com o diagnóstico de enfermidades quando associada à avaliação do quadro clínico e anamnese. Uma área que tem explorado essa técnica é a de animais silvestres, visando obter mais informações sobre as espécies em questão. Os dados concernentes à essa classe de animais são escassos, dificultando a avaliação do estado fisiológicos destes. Por isso, trabalhos científicos estão sendo realizados a fim de se estabelecer parâmetros fisiológicos de proteínas séricas ENCICLOPÉDIA BIOSFERA, Centro Científico Conhecer - Goiânia, v.11 n.22; p. 1142 
fracionadas por eletroforese, de animais tanto de vida livre quanto de cativeiro, com a intenção de auxiliar, posteriormente, na avaliação clínica de outros animais da mesma espécie (FAVERO et al., 2004; SANTAROSA et al., 2005; PIRES et al., 2008; FONTEQUE et al., 2009).

A eletroforese também contribui com o imunodiagnóstico, ao ser utilizada em técnicas como a de Western blotting, que detecta, caracteriza e quantifica múltiplas proteínas, realizando a imunodetecção, mesmo daquelas proteínas que estão em baixas quantidades (MIGUEL et al., 2012). A técnica ainda pode ser empregada na reprodução animal, auxiliando na sexagem de espermatozoides, fracionando proteínas presentes nas membranas destes (SCOTT, 2014).

Uma outra ferramenta da eletroforese explorada por diversos pesquisadores é a investigação do estado imunológico de neonatos, a fim de saber a eficiência do colostro, bem como a resposta individual na absorção e produção de imunoglobulinas (FAGLIARI et al., 1998; GODOY et al., 2006; HILL et al., 2007; FABRETTI et al., 2014).

$\mathrm{Na}$ área de produção animal, a eletroforese demonstrou ser um importante aliado, ao permitir a avaliação da eficiência da dieta no ganho de peso de bovinos (COSTA et al., 2006); a identificação e quantificação de proteínas musculares de frangos de corte também foi possível com o auxílio da técnica (FIGUEIRA, 2011). A composição proteica do leite também é determinada pela eletroforese (PETERS et al., 2012).

Além de contribuir com o diagnóstico e o prognóstico de várias doenças, a eletroforese também tem sido empregada na indústria alimentícia, com a finalidade de identificar fraudes em alimentos de origem animal, como leite e carnes. Já foi possível identificar a adição de soro de leite em bebidas lácteas (SOUZA et al., 2000), adulteração de leite caprino com leite bovino (EGITO et al., 2006), presença de soro de queijo em leite cru (LEITE \& NICOLAU, 2006), bem como a presença de substâncias não cárneas ou proteínas de outras espécies em produtos cárneos (DAGUER et al., 2010).

Muitos são os benefícios do emprego da eletroforese, justificando sua evolução na medicina veterinária. Além de auxiliar no esclarecimento de doenças, expressa alterações fisiológicas que podem ajudar no diagnóstico diferencial em algumas situações. A análise das frações de proteínas séricas permite uma melhor compreensão da fisiologia de diversas espécies, além de permitir o acompanhamento da evolução de diversas doenças (STOCKHAM \& SCOTT, 2011).

\section{CONSIDERAÇÕES FINAIS}

A eletroforese de proteínas é uma técnica simples, fornecendo informações importantes, não somente de forma fisiológica, mas também auxiliando no diagnóstico e no prognóstico de diferentes enfermidades e na identificação de processos inflamatórios e infecciosos. A técnica vem sendo utilizada em distintas áreas da medicina veterinária, como a clínica médica, a produção animal e a tecnologia de alimentos, bem como em diferentes tipos de animais. No entanto, percebe-se que esta metodologia pode ser mais explorada na clínica de animais silvestres. Assim sendo, a determinação de valores de referência faz-se necessária, levando em consideração as condições ambientais, nutricionais e fatores fisiológicos que podem, de alguma forma, interferir nesses dados.

O conhecimento dos principais componentes de cada fração proteica isolada durante a realização da eletroforese é de suma importância para a correta ENCICLOPÉDIA BIOSFERA, Centro Científico Conhecer - Goiânia, v.11 n.22; p. 1143 2015 
interpretação do exame. Dentre as eletroforeses existentes, todas apresentam ótimo desempenho no fracionamento proteico, apresentando distinções apenas no método de separação e no material utilizado, sendo algumas mais práticas que outras. Por isso, o conhecimento prévio das técnicas eletroforéticas existentes é fundamental para a escolha da melhor metodologia e, consequentemente, obtenção de um melhor resultado.

\section{REFERÊNCIAS}

AZEVEDO, M. O. Técnicas básicas em biologia molecular. Brasília: UNB; 2003. $211 p$.

BERTHOLO, L. C.; MOREIRA. H. W. Focalização isoelétrica na identificação das hemoglobinas. J Bras Med Lab. v.42, n.3, p.163-8, 2006.

BORGES, A. S.; AMORIM, R. M.; KUCHEMBUCK, M. R. G.; ARAÚJO, R. S.; SILVA, S. B.; SILVA, H. F.; BENESI, F. J.; MIRANDOLA, R.; MORGANO, M. Correlação entre a atividade sérica da ceruloplasmina e os teores sérico e hepático de cobre em novilhas Nelore. Arq Bras Med Vet Zootec. v.57, n.2, p.150-5, 2005.

BORGES, A.S.; FEITOSA, F. L. F.; BENESI, F. J.; BIRGEL, E. H.; MENDES, L. C. N. Influência da forma de administração e da quantidade fornecida de colostro sobre a concentração de proteína total e de suas frações eletroforéticas no soro sanguíneo de bezerros da raça Holandesa. Arq. Bras. Med. Vet. Zootec. v.53, p.629-34. 2001.

BURTIS, C. A.; ASHWOOD E. R. Tietz, Fundamentals of Clinical Chemistry 5th Ed., 2001.

$\mathrm{BUSH}$, B. M. Interpretação de resultados laboratoriais para clínicos de pequenos animais. São Paulo: Roca. 384 p. 2004.

CASTRO, T. A. M. G.; PIRES, R. M. L.; PIRES, F. G. Uso da eletroforese no diagnóstico de alterações morfológicas de sêmen de bovinos. Revista Científica Eletrônica de Medicina Veterinária. n.3, 2004.

CERÓN, J. J.; CALDIN, M.; MARTINEZ-SUBIELA, S. Electrophoresis and acute phase protein measurement In: WEISS, D. J.; WARDROP, K. J. editors. Schalm's veterinary hematology, 6th ed. lowa: Blackwell Publishing. p.1157-61. 2010.

CERÓN, J.J.; ECKERSALL, P. D.; MARTINEZ-SUBIELA, S. Acute phase proteins in dogs and cats: current knowledge and future perspectives. Vet Clin Pathol. v.34, p.85-99. 2005.

CERÓN, J.J.; MARTÍNEZ-SUBIELA, S. An automated spectrophotometric method for measuring canine ceruloplasmin in serum. Vet Res. v.35, p.671- 79, 2004.

COSTA, G. L.; SANDRINI, C. N. M.; JACOMINI, L. A.; SILVA, A. R. B.; SOUZA, S. N.; MAGGIOLI, M. F.; FIORAVANTI, M. C. S. Eletroforese das proteínas séricas de bovinos alimentados com diferentes tipos de capins. Universidade Federal de Goiás (UFG); 2006. 
CRIVELLENTE, F.; BONATO, M.; CRISTOFORI, P. Analysis of mouse, rat, dog, marmoset, and human serum proteins by capillary electrophoresis: comparison with agarose gel electrophoresis. Vet Clin Pathol. v.37, p.73-8, 2008.

DAGUER, H.; STEPHAN, M. P.; BERSOT, L. D. S. Perfil eletroforético de lombo suíno adicionado de proteínas não cárneas. Cienc Rural. v.40, p.404-10, 2010.

ECKERSALL, P. D.; BELL, R. Acute phase proteins: biomarkers of infection and inflammation in veterinary medicine. Vet J. v.185, p.23-27, 2010.

ECKERSALL, P. D. Proteins, proteomics and the dysproteinemias. In: KANEKO J. J.; HARVEY, J. W.; BRUSS, M. L. Clinical biochemistry of domestic animals. 6th ed. Burlington: Academic Press. p.117-155, 2008.

EGITO, A. S.; ROSINHA, G. M. S.; LAGUNA, L. E.; MICLO, L.; GIRARDET, J. M.; GAILLARD, J. L. Método eletroforético rápido para detecção da adulteração do leite caprino com leite bovino. Arq Bras Med Vet Zootec. v.58, p.932-9, 2006.

FABRETTI, A. K.; FONSECA, I. B.; PANCIERI, I. V. C.; KNUPP, F. C.; BORDINI, D. M.; PEREIRA, P. M. Avaliação clínica, laboratorial e perfil eletroforético na determinação do prognóstico de cães hospitalizados. Semina. v.35, n.6, p.3113-26, 2014,

FAGLIARI, J. J.; SANTANA, A. E.; MARCHIO, W.; CAMPOS FILHO, E.; CURI, P. R. Constituintes sanguíneos de vacas das raças Nelore (Bos indicus) e Holandesa (Bos taurus) e de bubalinos (Bubalus bubalis) da raça Murah durante a gestação, no dia do parto e no puerpério. Arq Bras Med Vet Zootec. v.50, n.3, p.273-82, 1998.

FAVERO, P. R.; LEONART, M. S. S.; NASCIMENTO, A. J. Eletroforese de proteínas de membrana eritrocítica no diagnóstico de doença hemolítica por defeito de membrana. Rev Acta Bioquim Clín Latinoam. v.38, n.3, p.313-7, 2004.

FIGUEIRA, P.T. Caracterização eletroforética de proteínas musculares de aves de interesse comercial. Universidade Estadual Paulista (UNESP); 2011.

FONTEQUE, J. H.; KOHAYAGAWA, A.; TAKAHIRA, R. K.; BIANCHI, E. H.; CHERUBINI, A. L.; PICCININ, A.; BRUDER, E. M.; RAMOS, P. R. R. Perfil eletroforético das proteínas séricas de serpentes Crotalus durissus terrificus (cascavel) criadas em cativeiro. Pesqui Vet Bras. v.29, p.457-60, 2009.

FRANÇA, R. T.; COSTA, M. M.; MARTINS, D. B.; PAGNONCELLI, M.; LEAL, M. L.; MAZZANTI, C. M.; PALMA, H. E.; KUNERT, C. P.; PAIM, F. C.; LOPES, S. T. A. Protein Profile of Buffaloes of Different Ages. Acta Sci Vet. v.39, n.4, p.995, 2011.

GEROU-FERRIANI, M.; MCBREARTY, A. R.; BURCHMORE, R. J.; JAYAWARDENA, K. G.; ECKERSALL, P. D.; MORRIS, J. S. Agarose gel serum protein electrophoresis in cats with and without lymphoma and preliminary results of tandem mass fingerprinting analysis. Vet Clin Pathol. v.40, n.2, p.159-73, 2011.

GOdoY, A. V.; SANTANA, A. E.; NAKAGE, A. P. M.; DE CÁPUA, M. L. B.; DE ENCICLOPÉDIA BIOSFERA, Centro Científico Conhecer - Goiânia, v.11 n.22; p. 1145 
ALMEIDA, T. L. Perfil eletroforético de proteínas séricas do sangue do cordão umbilical de cães. Cienc Rural. v.36, n.2, p.531-35, 2006.

HAGIWARA, M. K.; GERMANO, P. M. L. Eletroforese em acetato de celulose das proteínas séricas de Cães Normais e de Cães com sarna demodécica. Rev Fac Med Vet Univ Sao Paulo. v.11, n.1, p.69-81, 1974.

HARPER, H. A.; RODWELL, V. W.; MAYES, P. A. Manual de química fisiológica. 5 ed.. Tradução de J. Reinaldo Magalhães. São Paulo: Ateneu, 736 p. 1982.

HILL, J. A. G.; COSTA, D. W.; CASTRO, M. E. F.; HARTMANN, W.; BENESI, F. J. Proteína total, proteinograma Eletroforético e gamaglutamiltransferase de bezerras com 30 horas de vida no município de Campo Largo, Paraná. Rev. Acad. v.5, n.3, p.295-301, 2007.

ISRAILI, Z. H.; DAYTON, P. G. Human alpha-1-glicoprotein and its interactions with drugs. Drug Metab Rev. v.33, n.2, p.161-235, 2001.

JEPPSON, J. O.; LAURELL, C. B.; FRANZEN, B. Agarose gel electrophoresis. Clin Chem. v.25, n.4, p.629-38, 1979.

JOBIM, M. I. M.; OBERST, E. R.; SALBEGO, C. G.; SOUZA, D. O.; WALD, V. B.; MATTOS, R. C. Proteínas de baixo peso molecular do plasma seminal bovino relacionadas com a congelabilidade do sêmen através de eletroforese bidimensional em gel de poliacrilamida. Acta Sci Vet. v.31, n.1, p.21- 30, 2003.

JOHNSON, A. M.; MERLINI, G.; SHELDON, J.; ICHIHARA, K. Clinical indications for plasma protein assays: transthyretin (prealbumin) in inflammation and malnutrition. Clin Chem Lab Med. v.45, n.3, p.419-26, 2007.

KANEKO, J. J. In: KANEKO J. J.; HARVEY, J. W.; BRUSS, M. L. Clinical biochemistry of domestic animals. 5th ed. Burlington: Academic Press. p.130-39, 1997

KOGIKA, M. M.; PEREIRA, D. A.; ELIAS, F.; NOTOMI, M. K.; DELAYTE, E. H.; KAWAHARA, R.; HAGIWARA, M. K. Determinação sérica de haptoglobina, ceruloplasmina e glicoproteína ácida em cães com gastrenterite hemorrágica. Cienc Rural. v.33, n.3, p.513-17, 2003.

LANDERS, J. P. Capillary and Microchip Electrophoresis and Associated Microtechniques, 3 ed. Nova York: CRC Press.1598p, 2008.

LEITE, T. A.; NICOLAU, E. S. Ocorrência de soro ema amostras de leite cru refrigerado submetidas a diferentes tempos de armazenamento. In: Congresso de Pesquisa, Ensino E Extensão Da UFG - CONPEEX, 3 2006, Goiânia. Anais eletrônicos do XIIII Seminário de Iniciação Cientifica. Goiânia: Universidade Federal de Goiás (UFG); 2006.

MARTÍNEZ-SUBIELA, S.; TECLES, F.; PARRA, M. D.; CERÓN, J. J. Proteínas de fase aguda: conceptos básicos y principales aplicaciones clínicas en medicina 
veterinária. Anales Veterinaria Murcia. v.17, p.97-114, 2001.

MCGROTTY, Y. L. KNOTTENBELT, C. M.; RAMSEY, I. K.; REID, S. W. J.; ECKERSALL, P. D. Haptoglobin concentrations in canine hospital population. Vet Rec. v.152, p.562-564, 2003.

MCPHERSON, R. A. Specific Proteins. In: MCPHERSON, R. A.; PINCUS, M. R. Henry's Clinical Diagnosis and Management by Laboratory Methods. 22. ed. Philadelphia, Pa: Elsevier Saunders. p. 259- 272, 2011.

MENDES, L. S. C. Comparação entre a espectrofotometria e a eletroforese capilar para determinação de nitratos e nitritos em linguiça. [Dissertação]. Belo Horizonte: Universidade Federal de Minas Gerais, Escola de Veterinária; 2010.

MEYER, D. J.; HARVEY, J. W. Plasma Proteins In: Veterinary Laboratory Medicine Interpretation and Diagnosis. 3 ed. Missouri: Saunders Elsevier Inc. p.156-68, 2004.

MICKE, G. A. Otimização e simulação em eletroforese capilar [Tese]. São Paulo: Universidade de São Paulo, Instituto de Química; 2004.

MIGUEL, M. P.; MENEZES, L. B.; ARAÚJO, E. G. Western Blotting: A técnica e aplicações na pesquisa e rotina diagnóstica em medicina veterinária. Enciclopédia Biosfera. v.8, n.15, p.1704-1719, 2012.

NAOUM, P. C. Eletroforese: Hemoglobinopatias, Proteínas Séricas, Lipoproteínas e DNA. São Paulo: Editora Santos. 2012, 301p.

O'CONNELL, T.; HORITA, T.; KASRAVI, B. Understanding and Interpreting Serum Protein Electrophoresis. Americal Family Physician. v.71, p. 105-112, 2005.

PAULING, L.; ITANO, H. A.; SINGER, S. J.; WELLS, I. C. Sickle cell anemia, a molecular disease. Science. v.110, p.543, 1949.

PETERS, M. D. P.; SILVEIRA, I. D. B.; PEGORARO, C.; PEDROSO, C. E. S.; LOURENÇO, L. A.; CASAGRANDE, M. Perfil eletroforético qualitativo das proteínas do leite de vacas submetidas a manejo aversivo. Revista Thema. v.09, n.1, p.1-6, 2012.

PIRES, T. T.; ROSTAN, G.; BITTENCOURT, M. T. C. C.; ALMEIDA, M. A. O.; GUIMARAES, J. E. Eletroforese de proteínas séricas de tartarugas cabeçudas (Caretta caretta) de vida livre e mantidas em cativeiro no litoral norte da Bahia. Braz J Vet Res Anim Sci. v.45, p.121-126, 2008.

PLANELLAS, M.; BASSOLS, A.; SIRACUSA, C.; SACO, Y.; GIMENEZ, M.; PATO, $R$. Evaluation of serum haptoglobin and C-reactive protein in dogs with mammary tumors. Vet Clin Pathol. v.38, n.3, p.348-352, 2009.

PRINSEN, B. H. C. M. T.; DE SAIN-VAN DER VELDEN, M. G. M. Albumin turnover: experimental approach and its application in health and renal diseases. Clinica 
Chimica Acta. v.347, p.1-14, 2004.

RADKTE, J. Proteins. In: ANDERSON, S. C.; COCKAYNE, S. editors. Clinical Chemistry: Concepts and Applications. New York: McGraw Hill. p.203-221, 2003.

RICHES, P. G.; KOHN, J. Improved resolution of cellulose acetate membrane electrophoresis. Ann Clin Biochem. v.24, p.77-79, 1987.

SANTAROSA, K. T.; SILVA, R. C. R; SILVA, J. B. A.; SOTO-BLANCO, B. Valores de referência para o perfil eletroforético de proteínas séricas em cabras. Archives of Veterinary Science. v.10, n.3, p.46-48, 2005.

SCOTT, C. Efeitos da sexagem por citometria de fluxo sobre a composição proteica da membrana de espermatozoides bovinos. [Dissertação]. Botucatu: Universidade Estadual de São Paulo (UNESP), Faculdade de Medicina Veterinária e Zootecnia; 2014.

SILVA, R. O.; LOPES, A. F.; FARIA, R. M. D. Eletroforese de proteínas séricas: interpretação e correlação clínica. Rev Medica Minas. v.18, n.2, p.116-122, 2008.

SOUZA, E. M. T.; ARRUDA, S. F.; BRANDÃO, P. O.; SIQUEIRA, E. M. A. Electrophoretic analisys to detect and quantify additional whey in milk and dairy beverages. Food Sci Technol. v. 20, p.314-317, 2000.

SPUDEIT D. A.; DOLZAN, M. D.; MICKE, G. A. Conceitos básicos em Eletroforese Capilar. Scientia Chromatographica. v.4, n.4, p. 287-329, 2012.

STOCKHAM, S.; SCOTT, M. Fundamentos de Análises Clínicas Veterinárias. Capítulo 07, pág. 303, 341. Rio de Janeiro: Guanabara koogan. p.303-411, 2011.

TEIXEIRA, A. V. C.; ElOY, A. M. X.; FURTADO, J. R.; PINHEIRO, R. R.; PONTES, M. S. 1D mapping of seminal plasma proteins in Anglo-Nubian goats. Anim Reprod. v.6, n.4, p.516-525, 2009.

TISELIUS, A. A new apparatus for electrophoretic analysis of colloidal mixtures. Trans Farad Soc. v.33, p.524-531, 1937.

TIZARD, I. R. Imunologia veterinária: uma introdução. 8ª ed. Roca, São Paulo. 532p. 2008.

TORRES FILHO, H. M. Eletroforese de proteínas. Richet Nouvelles, Rio de Janeiro, v. 11, n. 3, p. 1-8, set. 2008.

VAVRICKA, S. R.; BURRI, E.; BEGLINGER, C.; DEGEN, L.; MANZ, M. Serum protein electrophoresis: an underused but very useful test. Digestion. v.79, p.20310, 2009.

VIEIRA, M. C. Eletroforetograma de proteínas séricas em cães linfomatosos, submetidos ao protocolo quimioterápico de Madison-Wisconsin [Tese]. Jaboticabal: Universidade Estadual Paulista, Faculdade de Ciências Agrárias e 
Veterinárias Campus de Jaboticabal; 2009.

YANG, F. Haptoglobin reduces lung injury associated with exposure to blood. Am. J. Physiol. Lung Cell Mol. Physiol. v.284, p.402-409, 2003. 